Вісник Харківського національного університету імені В.Н. Каразіна Серія "Математика, прикладна математика і механіка"

Том 88,2018 , с. $17-26$

УДК 517.9
Visnyk of V.N.Karazin Kharkiv National University Ser. "Mathematics, Applied Mathematics

and Mechanics"

Vol. 88, 2018, p. 17-26

DOI: $10.26565 / 2221-5646-2018-88-02$

\title{
Diffraction of the field of vertical electric dipole on the spiral conductive sphere in the presence of a cone
}

\author{
V. A. Rezunenko \\ V. N. Karazin Kharkiv National University, \\ 4, Svobody Sq., Kharkiv, 61022, Ukraine \\ varezunenko@yahoo.com
}

\begin{abstract}
The problem of diffraction of a vertical electric dipole field on a spiral conductive sphere and a cone has been solved. By the method of regularization of the matrix operator of the problem, an infinite system of linear algebraic equations of the second kind with a compact matrix operator in Hilbert space $\ell_{2}$ is obtained. Some limiting variants of the problem statement are considered.

Keywords: spiral conductive sphere; cone; vertical electric dipole; regularization method; system of equations of the second kind.
\end{abstract}

Резуненко В.О. Дифракція поля вертикального електричного диполя на спірально провідній сфері в присутності конуса. Розв'язана задача дифракції поля вертикального електричного диполя на спірально провідній сфері у присутності конуса. Методом регуляризації матричного оператора задачі отримано нескінченну систему лінійних алгебраїчних рівнянь другого роду з компактним матричним оператором у гільбертовому просторі $\ell_{2}$. Розглянуто деякі граничні варіанти постановки задачі.

Ключові слова: спірально провідна сфера; конус; вертикальний електричний диполь; метод регуляризації; система рівнянь другого роду.

Резуненко В. А. Дифракция поля вертикального электрического диполя на спирально проводящей сфере в присутствии конуса. Решена задача дифракции поля вертикального электрического диполя на спирально проводящей сфере в присутствии конуса. Методом регуляризации матричного оператора задачи получена бесконечная система линейных алгебраических уравнений второго рода с компактным матричным оператором в гильбертовом пространстве $\ell_{2}$. Рассмотрены некоторые предельные варианты постановки задачи.

Ключевые слова: спирально проводящая сфера; конус; вертикальный электрический диполь; метод регуляризации; система уравнений 2-го рода.

2010 Mathematics Subject Classification: 78A40; 78A45; 35A22; $97 \mathrm{~N} 42$.

\section{Introduction}

There is an interest to the problems of diffraction, electrodynamics, antenna techniques, optics, electrostatics, acoustics and other tasks on the sphere and on the cone. Different cases are considered: one sphere and one cone; two-three

(c) V. A. Rezunenko, 2018 
spheres and two-three cones; chains of hundreds of spheres and several cones nested into each other $[1,2,3]$. Increased attention to tasks on such surfaces and other resonance structures [4] has at least two reasons: 1) increased practical requirements for reducing the size of devices using parts of spheres and cones; 2 ) the emergence of new materials with new physical properties, for example, spiral conductive surfaces, nanomaterials, impedance structures. Such requests of practice lead to the need to reformulate standard problem statements, to create mathematical models of the studied processes, to create new numerical-analytical methods for solving new theoretical and applied problems. Among the numericalanalytical methods for solving a wide range of problems, an important role is played by the regularization method of the matrix or integral operator of the problem $[5,6]$. In this paper, based on a variant of the regularization method of the matrix operator of the problem [2]-[6], [11, 12], [14]-[18], we construct a numericalanalytical algorithm for solving the problem of diffraction of a vertical electric dipole field on a spiral conductive sphere in the presence of an ideally conductive cone. An efficiently solvable infinite system of linear algebraic equations of the second kind with a compact operator is obtained [3]. Some limiting variants of the problem statement are considered.

\section{Formulation of the problem}

We place the origin of the Cartesian $(x, y, z)$ and spherical $(r, \theta, \varphi)$ coordinate systems in the centre of a spiral conductive hollow sphere of radius $a$ [3]. The top of an ideally conductive cone is in the center of the sphere, and the axis of the cone coincides with the negative semi-axis of the axis $0 z$. The opening angle of the cone is counted from the positive semi-axis of the axis $0 z$ and is assumed to be equal $\gamma$, $\gamma \in(0, \pi)$. The cone is the ideally conductive. We isolate the cone and the sphere by a non-conductive infinitely thin and infinitely narrow tape. We place a vertical electric dipole at the point $(0,0, b), a<b$. The moment $\vec{P}$ of the dipole is oriented along the axis $0 z$ and $|\vec{P}|=1$. The dipole field creates, in particular, secondary fields outside of the sphere and inside of the sphere, and also creates electric currents on the surfaces of the sphere and the cone. The time dependence of the dipole field and secondary fields is assumed to be harmonic with the frequency $\omega=2 \pi / \lambda, \lambda$ is the wavelength of the dipole field. The electric currents, arising on the surface of the sphere under the influence of its spiral conductivity, change the standard direction along the meridians. Currents can pass on the surface of the sphere only along lines directed at an angle $0 \leq \beta<\pi / 2$ to the meridians. For an observer located at the pole of the sphere, this direction corresponds to the movement of the currents clockwise at an angle $\beta$ to meridians. The sphere, the cone, and the currents on the sphere are axisymmetric. In this paper, we consider two independent variants of current movement along the surface of a sphere [3]. The first variant corresponds to the movement of currents at an angle $(+\beta)$ to the meridians on the sphere, and the second one corresponds to the movement of currents at an angle $(-\beta)$ to the meridians on the sphere [3]. Consider briefly the formulation of the problem [3]. We will use the method of partial domains. Full 
fields inside of a sphere and secondary fields outside of a sphere should be solutions to the Maxwell's equations, satisfy material equations, satisfy radiation conditions at infinity, have bounded energy in any restricted volume of space, including the top of the cone, and have the required feature at the dipole placement point. The boundary conditions on the surface of the sphere $r=a, \theta \in[0, \gamma), \varphi \in[0,2 \pi]$ are as follows [3], [7]-[12]. The tangential components of the total magnetic fields $H_{\varphi}, H_{\theta}$ and the tangential components $E_{\varphi}, E_{\theta}$ of the full electric fields are related, in particular, by means of a multiplier like $\operatorname{tg}( \pm \beta)$

$$
\begin{gathered}
\left(H_{\varphi}^{(2)}+H_{\varphi}^{(0)}-H_{\varphi}^{(1)}\right) \operatorname{tg}( \pm \beta)+\left(H_{\theta}^{(2)}-H_{\theta}^{(1)}\right)=0, \\
E_{\theta}^{(1)}+E_{\varphi}^{(1)} \operatorname{tg}( \pm \beta)=0, \quad E_{\theta}^{(1)}=E_{\theta}^{(0)}+E_{\theta}^{(2)}, \quad E_{\varphi}^{(2)}=E_{\varphi}^{(1)},
\end{gathered}
$$

The boundary conditions on the surface of the cone are set as follows: the vector products of the complete electromagnetic fields and the external normal $\vec{n}_{1}$ to the surface of the cone are zero

$$
\begin{gathered}
E^{(1)} \otimes \vec{n}_{1}=0, \quad r \in[0, a), \quad \theta=\gamma, \quad \varphi \in[0,2 \pi], \\
\left(E^{(2)}+E^{(0)}\right) \otimes \vec{n}_{1}=0, \quad r \in(a, \infty), \quad \theta=\gamma, \quad \varphi \in[0,2 \pi],
\end{gathered}
$$

where in formulas (1)-(4) the superscripts of the electromagnetic field vectors refer to the source field, to the field inside the sphere, $r<a$, the field outside $r>a$, the sphere, respectively. In this formulation, problem (1)-(4) has a unique solution [13]. We note that in this work, on the basis of [3], [7]-[12] the boundary conditions on a spiral conductive sphere are refined. The continuity of the tangential components of the total electric field on a spiral conducting sphere is required. We also clarify the difference in representations and transformations of the Debye potentials for TM and TE waves and the differences in the corresponding Fourier series. We note that the introduction of additional boundary conditions naturally leads to the complication of the method for solving the problem and to obtaining new systems of algebraic equations of the second kind.

\section{Fourier series for Debye scalar potentials}

Since the time of Debye (near 1903), scalar and vector potentials have been used successfully to reduce the dimensionality of problems, in particular, problems of diffraction of electromagnetic waves, acoustics, and electrostatics. To solve these and other problems on the coordinate surfaces used, in particular, the method of separation of variables in 11 coordinate systems. The type of representation of potentials depends not only on the shape of the surface and the type of boundary conditions on the surface. The main ones are, in particular, the methods of direct and inverse integral transformations of differential equations for potentials, as well as the method of Green functions. Both methods are in most cases used in conjunction with the Fourier method of separation of variables. Thus, in [8]-[10], the method of integral transformations and the method of separation of Fourier 
variables were among the first used to solve the problem of diffraction of a vertical electric dipole field on an ideally conductive cone. On the basis of [3], [7]-[10], we write in the spherical coordinate system the Fourier series for the Debye electric potential of the dipole field in the presence of an ideally conductive cone

$$
U^{(0)}=\sum_{m=1}^{\infty} F_{m}^{(1)} M_{m} P_{\nu_{m}}(\cos \theta) \begin{cases}{\left[\psi_{\nu_{m}}(k r) \xi_{\nu_{m}}(k b)\right] /(k r),} & r<b, \\ {\left[\xi_{\nu_{m}}(k r) \psi_{\nu_{m}}(k b)\right] /(k r),} & r>b,\end{cases}
$$

where

$$
M_{m}=\left[\left.(k b)^{3} \sin \gamma \frac{\partial}{\partial \nu} P_{\nu}(\cos \gamma)\right|_{\nu=\nu_{m}} P_{\nu_{m}}^{1}(\cos \gamma)\right]^{-1}, \quad F_{m}^{(1)}=2 \nu_{m}+1,
$$

$\psi_{\nu_{m}}(k r), \xi_{\nu_{m}}(k b)$ are spherical Bessel functions of the first kind and, accordingly, Hankel of the third kind in the Debye notation, $P_{\nu_{m}}(\cos \theta)$ - Legendre functions of the first kind of the $\nu_{m}$ degree of the zero order of the argument $\cos \theta, P_{\nu_{m}}^{1}(\cos \gamma)-$ associated Legendre functions of the first kind of the $\nu_{m}$ degree of the first order of the argument $\cos \gamma$. The spectral parameters $\nu_{m}$ and new parameters $\mu_{n}$ satisfy

the transcendental equations $P_{\nu_{m}}(\cos \gamma)=0$ and $P_{\mu_{n}}^{1}(\cos \gamma)=0$. The roots of these equations $\nu_{m}$ (and $\mu_{n}$ ) are simple and do not coincide for $m, n \geq 1$. The magnetic potential $V^{(0)}$ of the dipole is zero by the definition.

We look for the secondary potentials in the form of Fourier series (5), (6)

$$
\begin{array}{ll}
U^{(1)}=\sum_{m=1}^{\infty} F_{m}^{(1)} A_{m} P_{\nu_{m}}(\cos \theta) \psi_{\nu_{m}}(k r) /(k r), & r<a, \\
V^{(1)}=\sum_{n=1}^{\infty} F_{n}^{(2)} B_{n} P_{\mu_{n}}(\cos \theta) \psi_{\mu_{n}}(k r) /(k r), & r<a, \\
U^{(2)}=\sum_{m=1}^{\infty} F_{m}^{(1)} C_{m} P_{\nu_{m}}(\cos \theta) \xi_{\nu_{m}}(k r) /(k r), & r>a, \\
V^{(2)}=\sum_{n=1}^{\infty} F_{n}^{(2)} D_{n} P_{\mu_{n}}(\cos \theta) \xi_{\mu_{n}}(k r) /(k r), & r>a,
\end{array}
$$

where

$$
F_{n}^{(2)}=2 \mu_{n}+1, \quad n \geq 1 .
$$

\section{The system of four functional equations containing fractional degree Legendre functions}

To find the coefficients $A_{m}, B_{n}, C_{m}, D_{n}, m, n \geq 1$ of the Debye potentials (7) (11), we construct a system of four functional equations. Note that the sequences of coefficients $\left\{A_{m}\right\},\left\{B_{n}\right\},\left\{C_{m}\right\},\left\{D_{n}\right\}, m, n \geq 1$ belong to Hilbert spaces with different weights. We first use the boundary conditions (1)-(4), perform linear 
transformations to obtain a system of four functional equations which connect all desired coefficients. For example, the first two equations are as follows

$$
\begin{gathered}
\sum_{n=1}^{\infty} F_{n}^{(2)}\left[D_{n} \xi_{\mu_{n}}^{1}(k a)-B_{n} \psi_{\mu_{n}}^{1}(k a)\right] P_{\mu_{n}}^{1}(\cos \theta)+(i k a)(\operatorname{tg}( \pm \beta)) \\
\times \sum_{m=1}^{\infty} F_{m}^{(1)}\left[C_{m} \xi_{\nu_{m}}(k a)-M_{m} \psi_{\nu_{m}}(k a) \xi_{\nu_{m}}(k b)-A_{m} \psi_{\nu_{m}}(k a)\right] P_{\nu_{m}}^{1}(\cos \theta)=0,
\end{gathered}
$$

where $\theta \in[0, \gamma]$,

$$
\begin{gathered}
\sum_{n=1}^{\infty} B_{n} F_{n}^{(2)} \psi_{\mu_{n}}(k a) / \xi_{\mu_{n}}^{1}(k a) P_{\mu_{n}}(\cos \theta) \\
+(i k a)(\operatorname{tg}( \pm \beta)) \sum_{m=1}^{\infty} F_{m}^{(1)}\left[A_{m} \xi_{\nu_{m}}^{1}(k a)-M_{m} \xi_{\nu_{m}}^{1}(k b)\right] P_{\nu_{m}}^{1}(\cos \theta)=0,
\end{gathered}
$$

where $\theta \in[0, \gamma]$. For functions $\xi_{\mu_{n}}^{1}(k a), \psi_{\mu_{n}}^{1}(k a), \xi_{\nu_{m}}^{1}(k a), \xi_{\nu_{m}}^{1}(k b)$ the superscript 1 denotes the differentiation by argument $k a$ or $k b$, respectively.

\section{The system of linear algebraic equations of the second kind}

The resulting system of four functional equations is a system of the first kind with respect to the coefficients being sought $A_{m}, B_{n}, C_{m}, D_{n}, m, n \geq 1$ and it is ineffective for directly solving the problem. Note that in solving problems of electrodynamics, electrostatics, acoustics and other problems on a sphere with aperture, the use of an integral representation of the Abel type for the Legendre functions [11]-[12], [14]-[18] is recommended. In our case, for example, for equation (13), the Abel representation is ineffective. The resulting functional equations require, in particular, additional decomposition over new orthogonal classes of functions.

Indeed, we use the generalized integral representations of Abel type

$$
P_{\nu_{m}}(\cos \theta)=\pi^{-1} \sqrt{2} \int_{0}^{\theta}(\cos \phi-\cos \theta)^{-0.5} \cos \left(\nu_{m}+\frac{1}{2}\right) \phi d \phi,
$$

in (13) for the Legendre functions. Then we change the order of summation and integration in the functional equation using the uniform convergence of the series. We get an integral equation of Abel type with the kernel ( $\cos \phi-$ $\cos \theta)^{-0.5}$. Solving an integral equation using the inverse Abel transformation, we received a new functional equation in the form of series containing functions $\cos \left(\nu_{m}+\frac{1}{2}\right) \phi, \cos \left(\mu_{n}+\frac{1}{2}\right) \phi, m, n \geq 1$. These functions are not orthogonal in the space $L_{2}(0, \gamma)$. The Fourier series of these functions must be redeveloped in the corresponding functional space. Let us transform system (12), (13) and the remaining two functional equations into a system of algebraic equations of the second kind as follows. First, we apply the discrete Fourier transform to each 
functional equation, taking into account, in particular, the orthogonality of the associated Legendre functions $P_{\mu_{n}}^{1}(\cos \theta)$ with weight $\sin \theta[8]-[10]$

$$
\begin{gathered}
N_{n, n}^{(2)}=\int_{0}^{\gamma}\left(P_{\mu_{n}}^{1}(\cos \theta)\right)^{2} \sin \theta d \theta=-\left.\frac{\mu_{n}\left(\mu_{n}+1\right)}{2 \mu_{n}+1} \sin \gamma P_{\mu_{n}}^{1}(\cos \gamma) \frac{\partial}{\partial \mu} P_{\mu}^{1}(\cos \gamma)\right|_{\mu=\mu_{n}}, \\
N_{m, n}^{(2)}=0, \quad m \neq n, m, n \geq 1 .
\end{gathered}
$$

The resulting auxiliary system of four linear equations includes, for example, the equation

$$
\begin{gathered}
N_{n, n}^{(2)} F_{n}^{(2)}\left[D_{n} \xi_{\mu_{n}}^{1}(k a)-B_{n} \psi_{\mu_{n}}^{1}(k a)\right]=-(i k a) \operatorname{tg}( \pm \beta) \\
\times \sum_{m=1}^{\infty} F_{m}^{(1)}\left[C_{m} \xi_{\nu_{m}}(k a)-M_{m} \psi_{\nu_{m}}(k a) \xi_{\nu_{m}}(k b)-A_{m} \psi_{\nu_{m}}(k a)\right] J_{n, m},
\end{gathered}
$$

where

$$
J_{n, m}=\frac{\mu_{n}\left(\mu_{n}+1\right)}{\left(\mu_{n}-\nu_{m}\right)\left(\nu_{m}+\mu_{n}+1\right)} \sin \gamma P_{\mu_{n}}(\cos \gamma) P_{\nu_{m}}^{1}(\cos \gamma) .
$$

Let us return to the system of four functional equations, including (12), (13) and (14)-(17). Based on it, to find coefficients $B_{n}, n \geq 1$, for potential (8), we construct a system of linear equations of the second kind. For this, we first exclude the coefficients $A_{n}, C_{m}, D_{n}, m, n \geq 1$, from the auxiliary system. In this case, we solve the auxiliary system, use the equality for Wronski determinants $W\left(\psi_{\nu_{m}}(k a), \xi_{\nu_{m}}(k a)\right)=W\left(\psi_{\mu_{n}}(k a), \xi_{\mu_{n}}(k a)\right), m, n \geq 1$ and perform some linear transformations. So, in the auxiliary double sum, using uniform convergence of the series, we change the order of summation and get

$$
\sum_{m=1}^{\infty} T_{m} J_{n, m} \sum_{k=1}^{\infty} B_{k} R_{k} J_{k, m}=\sum_{k=1}^{\infty} B_{k} R_{k} \sum_{m=1}^{\infty} J_{k, m} T_{m} J_{n, m}
$$

With these operations, we separate and inverse the main part of the matrix operator of the problem. As a result, we obtained an infinite system of linear algebraic equations of the second kind (ISLAE-II)

$$
B_{n}=-[(k a) \operatorname{tg}( \pm \beta)]^{2} \sum_{s=1}^{\infty} B_{s} \varepsilon_{s, n}-[(i k a) \operatorname{tg}( \pm \beta)] \sum_{m=1}^{\infty} F_{m}^{(3)} J_{n, m}
$$

where

$$
\begin{gathered}
\varepsilon_{s, n}=\left[F_{s}^{(2)} / F_{n}^{(1)}\right] \psi_{\mu_{s}}^{1}(k a) \xi_{\mu_{n}}(k a)\left[1 / N_{n, n}^{(2)}\right] \\
\times \sum_{m=1}^{\infty}\left[N_{m, m}^{(1)} \psi_{\nu_{m}}^{1}(k a) \xi_{\nu_{m}}^{1}(k a)\right]^{-1} J_{s, m} J_{m, n}, \\
F_{m}^{(3)}=\frac{F_{m}^{(1)}}{F_{m}^{(2)}} M_{m} \frac{\xi_{\mu_{n}}(k b) \xi_{\mu_{n}}(k a)}{\xi_{\nu_{m}}^{1}(k a)} \frac{1}{N_{n, n}^{(2)}}, \quad m, n \geq 1 .
\end{gathered}
$$




$$
N_{m, m}^{(1)}=\left.\frac{\nu_{m}\left(\nu_{m}+1\right)}{2 \nu_{m}+1} \sin \gamma P_{\nu_{m}}^{1}(\cos \gamma) \frac{\partial}{\partial \nu} P_{\nu}^{1}(\cos \gamma)\right|_{\nu=\nu_{m}}
$$

In the matrix elements $\varepsilon_{s, n}$ and in the second series of the system (18), the convergence is uniform on the set $k a \in(0, \infty), k a<k b, \beta \in[0, \pi / 2)$ and $\gamma \in(0, \pi)$. As a result, ISLAE-II with a compact operator $M^{(1)}$ in space $\ell_{2}$ and a right-hand $B^{(1)}$ column in $\ell_{2}$ are obtained [19]

$$
B=M^{(1)} B+B^{(1)}
$$

where $B=\left(B_{1}, B_{2}, B_{3}, \ldots, B_{n}, \ldots\right)^{T}$ is the vector of magnetic potential coefficients sought (8), where the superscript $T$ denotes the transposition of the row into a column, $M^{(1)}=\left\{-(k a)^{2}\left(\operatorname{tg}^{2}( \pm \beta)\right) \times \varepsilon_{s, n}\right\}_{s, n=1}^{\infty}$ is the system matrix, $B=\left(B_{1}, B_{2}, B_{3}, \ldots, B_{n}, \ldots\right)^{T}=\left(\left\{-(i k a)(\operatorname{tg}( \pm \beta)) \times \sum_{m=1}^{\infty} F_{m}^{(3)} J_{n, m}\right\}_{n=1}^{\infty}\right)^{T}-$ right column of the system.

\section{Conclusions}

1. System (19) is effectively solvable analytically and numerically in Hilbert space $\ell_{2}$. At small angles $\gamma,(0<\gamma<<1)$, (and large angles $\gamma,(0<<\gamma<\pi)$, the system is analytically solvable for any values $0<k a<k b$.

2. To find the coefficients $A_{m}, m \geq 1$ and potential $U^{(1)}(7)$, it is necessary to build a new ISLAE-II. At the same time, to obtain an ISLAE-II, we use the same regularization method for the matrix operator of the diffraction problem, as in deducing the system (19). In this case to find the coefficients $C_{m}, D_{n}, m, n \geq 1$ and potentials (9) and (10), we use linear transformation of variables.

3 . Let us discuss the limiting case of the problem statement, when the sphere loses its spiral conductivity and becomes ideally conducting $(\beta \rightarrow 0)$. In this case $[2,3]$, the problem of diffraction of a dipole field on such a sphere in the presence of a cone, the desired coefficients of the Fourier series of Debye potentials (8)-(10) can be found explicitly. So, when $\beta=0$ we find the solution to the system (18) and we get the explicit value of the coefficients $B_{n}: B_{n}=0, n \geq 1$. Also we obtain the explicit values of the limiting components of the diffracted field.

4. In another limiting case, when the sphere is absent $(k a=0)$, the components of the desired fields of diffraction of a dipole field on a cone are known and are calculated explicitly from a given dipole potential $U^{(0)}(5),(6)$.

5. The parametric equations $x=\sin ( \pm \eta) \times \cos ( \pm 14 \eta), y=\sin ( \pm \eta) \times$ $\sin ( \pm 14 \eta), z=1+\cos ( \pm \eta), \eta \in[0, \pi / 2)$ are refined for two variants of the movement of currents along the surface of a spiral conductive sphere corresponding to fixed angles $\pm \beta_{0}$ to the meridians on the sphere.

6. The approach developed in this paper is applicable, for example, to the problem of diffraction of a dipole field on a spiral conductive sphere, which has a circular hole between a sphere and a cone, as well as for other applied problems. 


\section{REFERENCES}

1. H. Nakano, T. Shimizu, H. Kataoka, J. Yamauchi. Circularly and linearly polarized waves from a metamaterial spiral antenna. International Symposium AP and USNC-URSI RSM. - 2014 - July 6-11. -- P. 226.2.

2. D.B. Kyruliak, Z.T. Nazarchuk, O.B. Trishchuk. Axially-symmetrical TM waves diffraction by sphere-cone cavity. Progress in electromagnetics research. B. - 2017. -Vol. 73.- P. 1-17.

3. V.A. Rezunenko. The scattering of the vertical electric dipole field by a spiral conductive sphere with a load. Materials of the 18th International Scientific Conference Named After Academic of Mikhail Kravchuk. 7-10 October 2017, Lutsk-Kyiv. - V. 1. - P.126-129, (in Russian).

4. V.F. Kravchenko, Yu.K. Sirenko, K.Yu. Sirenko. Electromagnetic waves transformation and radiation by the open resonant structures. Modeling and analysis of transient and steady-state processes. - M. - Physmatlit. - 2011. 320p, (in Russian).

5. Z.S. Agranovich, V.A. Marchenko, V.P. Shestopalov. Electromagnetic wave diffraction on plane metallic gratings. Journal of Technical Physics. - 1962. T.32. - Issue 4. - P. 381-394, (in Russian).

6. V.P. Shestopalov, L.N. Litvinenko, S.A. Masalov, V.G. Sologub. Diffraction of waves by gratings. -Kharkov. - Kharkov University Press. - 1973.- 288 p. (in Russian).

7. K. Mei, M. Meyer. Solution to spherical anisotropic antennas. - IEEE trans., - 1964, AP-12, - P.459.

8. M.I. Kontorovich, N.N. Lebedev. About one method of solving some problems of the theory of diffraction and related problems. Journal of Experimental and Theor. Physics. - 1938. - Vol. 10-11. - P. 1192 - 1206, (in Russian).

9. N.N. Lebedev, M.I. Kontorovich. On the application of the treatment formulas to some problems of electrodynamics. Journal of Experimental and Theor. Physics. - 1939. - V.9. - Vol. 3. - P. 729, (in Russian).

10. L.B. Felsen, N. Marcuvitz. Radiation and scattering of waves. Prentice-Hall Microwaves and Fields Series. Prentice-Hall, Inc., Englewood Cliffs, N.J., 1973. xxxii +888 pp.

11. V.A. Rezunenko. The field of the vertical electrical dipole placed above the spiral conductive unclosed sphere. Visnyk of V.N. Karazin Kharkiv National University. Ser. Mathematics, Applied Mathematics and Mechanics. - Vol. 81. - 2015. - P. 10-19. 
12. V. A. Rezunenko. The field diffraction of current ring on a spiral conductive sphere with a hole. The X-th International Conference on Antenna Theory and Techniques ICATT'2015, KhNURE, Kharkiv, 21-24 April, 2015. Proceedings. - P. 129-131.

13. O.A. Ladyzhenskaya. The boundary value problems of mathematical physicist. Translated from the Russian by Jack Lohwater. Applied Mathematical Sciences. - New York. - 1985. - 322p.

14. V. A. Rezunenko. Integral equation of the electrostatic problem for a spherical segment and a dielectric rounding of a cone, Visnyk of V.N.Karazin Kharkiv National University. Ser. Mathematics, Applied Mathematics and Mechanics. - 2006. - N.749. Issue 56. - P. 50-56, (in Russian).

15. I.A. Vyazmitinov, S. S. Vyazmitinova, V.A. Rezunenko. The calculation of the potential of electron-optical systems with unloaded spherical cathode. 'Radio. Engineering'. Ukrainian interdepartmental scientific and technical collection. 89. - 1990. - P.130-133, (in Russian).

16. V. A. Rezunenko. The potential of a spherical segment within a spherical layer with a circular aperture. Visnyk of V.N. Karazin Kharkiv National University. Ser. Radiotechnics and Electronics. -834 (13). - 2008. -P.120-126, (in Russian).

17. V.A. Rezunenko, I. A. Vyazmitinov, L.V. Udyanskaya, V.P. Shestopalov. Antennas characteristics of spherical reflector which is working at Helmholtz resonance excitation. International Scientific and Technical Conference "Modern Radar". - Kiev. - 1994. -P. 72-76.

18. V. A. Rezunenko, S.V. Roshchupkin, E. I. Radchenko. Diffraction field of the vertical dipole from sphere with aperture, screening by the dielectical layer. The VI International Conference ICATT'2007. SNTU, Sevastopol. - 2007. Proceedings. - P. 128-130.

19. V.A. Sadovnichy. Theory of the operators. -M.: -High School. -1999 . -368p, (in Russian).

Резуненко В.О. Дифракція поля вертикального електричного диполя на спірально провідній сфері в присутності конуса. Розв'язана задача дифракції електромагнітного поля вертикального електричного диполя на спірально провідній сфері у присутності ідеально провідного кругового конуса. Центр сфери і вершина конуса розміщено у початку декартової та сферичної систем координат. Диполь розміщений на вісі симетрії сфери і конуса та поза сфери і конуса. Момент диполя орієнтовний вздовж вісі симетрії сфери та конуса. Електричні токи на поверхні сфери, в наслідок спіральної провідності сфери, можуть текти під фіксованим кутом до кожного меридіану. Повні електромагнітні поля повинні задовольняти, зокрема, рівняння Максвела, матеріальні рівняння, умови скінченності енергії у довільному обмеженому об'єму, граничні умови. Для розв'язку задачі будемо використовувати метод часткових областей. В сферичній системі координат 
використані чотири скалярні електричні і магнітні потенціали Дебая. Потенціали Дебая представлені рядами Фур'е по функціям Бесселя, функціям Ханкеля, а також по функціям Лежандра дробових спектральних параметрів. Граничні умови на поверхні спірально провідної сфери неперервно пов'язують тангенціальні компоненти електричних і магнітних полів. Потрібно для чотирьох потенціалів Дебая знайти коефіцієнти чотирьох рядів Фур'е. Послідовності коефіцієнтів цих рядів шукаємо у Гільбертових просторах зі своєю вагою. Для пошуку коефіцієнтів використовуємо граничні умови та одержуємо чотири функціональні рівняння. Їх прямий розв'язок неефективний. Також не $\epsilon$ ефективним застосування у функціональних рівняннях для функцій Лежандра узагальненого інтегрального представлення типа Абеля. У даній роботі для застосування метода регуляризації матричного оператора задачі до кожного з чотирьох рівнянь застосовуємо дискретне перетворення Фур'е. Далі використовуємо рівність визначників Вронського для функцій Бесселя з дробовими індексами. Після лінійних перетворень та застосування зміни порядків підсумування у допоміжних подвійних числових рядах одержуємо нескінченну систему лінійних алгебраічних рівнянь другого роду (НСЛАР-11). В цій системі матричний оператор $є$ компактним у гільбертовому просторі числових послідовностей. Система ефективно розв'язна у гільбертовому просторі аналітично для граничних значень параметрів задачі і чисельно для довільних параметрів. У роботі розглянуто деякі граничні варіанти постановки задач.

Ключові слова: спірально провідна сфера; конус; вертикальний електричний диполь; метод регуляризації; система рівнянь другого роду.

Article history: Received: 15 October 2018; Final form: 29 November 2018; Accepted: 1 December 2018. 